J. Amer. Soc. Hort. Sci. 116(4):724-727. 1991.

\title{
Inheritance of Resistance to Colletotrichum Species in Strawberry
}

Creighton L. Gupton and Barbara J. Smith

U.S. Department of Agriculture, Agricultural Research Service, Small Fruit Research Station, P. O. Box 287, Poplarville, MS 39470

\author{
Additional index words. anthracnose crown rot, strawberry breeding, heritability, genetic variance, epistasis, Fragaria \\ $\times$ ananassa
}

Abstract. Experiments were conducted to estimate the relative importance of additive ( $\left.\boldsymbol{\sigma}_{\mathbf{a}}^{\boldsymbol{2}}\right)$ and dominance ( $\left.\boldsymbol{\sigma}_{\mathbf{d}}^{\boldsymbol{2}}\right)$ genetic variances and non-allelic interactions $\left(\boldsymbol{\sigma}_{\mathbf{i}}^{\mathbf{2}}\right)$ in the inheritance of resistance to Colletotrichum spp. in strawberry (Fragaria $\times$ ananassa Duch.). Progeny of 40 parents crossed in a Comstock and Robinson Design II Mating scheme were inoculated with three isolates of $C$. fragariae and one isolate of $C$. acutatum. Disease development on each plant was rated visually. Variance components were estimated and converted to genetic variances. Estimates of $\boldsymbol{\sigma}_{\mathbf{d}}^{2}$ were six to 10 times higher than those for $\boldsymbol{\sigma}_{\mathbf{a}}^{2}$. Within-family variance not accounted for by $\boldsymbol{\sigma}_{\mathbf{a}}^{2}$ and $\boldsymbol{\sigma}_{\mathbf{d}}^{2}$ equaled $35 \%$ and $38 \%$ of the total genetic variance in females and males, respectively, indicating probable epistatic effects. The frequency distribution of disease severity ratings was bimodal in both experiments, suggesting major gene action. Narrow-sense heritability estimates were 0.37 and 0.26 , and broad-sense heritability estimates were 0.87 and 0.85 for females and males, respectively. Narrow-sense heritability estimates are probably sufficient to produce gains from recurrent selection. Gains from selection of clonal value should be possible because of the high broad sense heritability estimates. It appears feasible to establish a broad genetic-based population resistant to Colletotrichum spp. from which selections could be evaluated per se and/or recombined to produce improved populations.

Anthracnose crown rot, caused by Colletotrichum fragariae Brooks, is probably the most limiting factor in strawberry production in the Gulf-South states of the United States. Smith and Black (1986) found that $C$. acutatum Simmonds caused a similar crown rot. The disease has revolutionized strawberry culture in the traditional Louisiana production region, causing growers to change cultivars and plant production method. Plants are now obtained from nurseries outside the Gulf South rather than being produced on the farms. The locally adapted 'Tangi' is no longer widely grown because it is not available from nurseries outside of Louisiana. 'Chandler' and other California cultivars currently grown because of their availability appear to be susceptible to common leaf spot (Mycosphaerella fragariae), gray mold fruit rot (Botytis cinerea), angular leaf spot (Xanthomonas fragariae), and $C$. acutatum fruit rot when grown in Louisiana.

We found no reports on the inheritance of resistance to $C$. fragariae in the literature. Such information is needed to determine the most efficient breeding methodology. A preliminary study (Expt. 1) was conducted in 1985 to determine the feasibility of estimating genetic and environmental variances in a small population using the available C. fragariae isolates, inoculation technique, and disease severity scale (Smith and Black, 1987). Progenies from many parents with a broad genetic base were evaluated in 1988 (Expt. 2) to obtain better estimates of the relative importance of additive and dominance genetic variances and non-allelic interactions in the inheritance of resistance to $C$. fragariae in strawberry.

\section{Materials and Methods}

Genetic and environmental variance (small population) (Expt. 1). Six strawberry clones that varied in origin and reported response to $C$. fragariae (Table 1) were designated randomly as three male and three female parents. Each female was crossed with each male parent to produce nine full-sib families. As many

Received for publication 15 Oct. 1990. The cost of publishing this paper was defrayed in part by the payment of page charges. Under postal regulations, this paper therefore must be hereby marked advertisement solely to indicate this fact. as 57 seedlings from each family were propagated by runners to produce four genetically identical plants from each seedling. One of the four plants originating from a seedling was inoculated with each of three C. fragariae isolates and one $C$. acutatum isolate so that each isolate was tested on identical genotypes. C. fragariae isolates CF-63, LA-1, and Fla-1 were among the most virulent isolates evaluated in a previous study and were isolated from strawberry plants in three states (Smith and Black, 1990). In the same study, Goff was the most virulent $C$. $a c u$ tatum isolate.

Inoculum of each isolate was prepared at $1.5 \times 10^{6}$ conidia/ $\mathrm{ml}$ concentration and sprayed on the plants to runoff (Smith and Black, 1987). Plants were inoculated with $C$. fragariae isolate CF-63 on 4 Dec., LA-1 on 12 Dec., and FLA-1 on 20 Dec. 1985, and C. acutatum isolate Goff on 21 Jan. 1986. The inoculated plants were incubated in an unlighted dew chamber at $31 \pm 2 \mathrm{C}$ and $100 \% \mathrm{RH}$ for $48 \mathrm{~h}$ and then returned to a greenhouse held between 20 and $28 \mathrm{C}$ and a 16-h photoperiod. After 12 days, the disease severity of each plant was rated as follows: $0=$ no disease symptom, $1=$ fleck on petiole, $2=$ lesions 3 to $10 \mathrm{~mm}$ long, $3=$ lesions 11 to $20 \mathrm{~mm}$ long, $4=$ lesions $>20 \mathrm{~mm}$ long, $5=$ youngest leaf wilted, and $6=$ plant dead.

Environmental variance $\left(\sigma_{\mathrm{v}}^{2}\right)$ was estimated as the withinclone variance of 148 plants from 37 clones inoculated with isolate CF-63. Analyses of genetic variance were performed by general linear model procedures (SAS Institute, Inc., Cary, N.C.). Variance components were then estimated by standard methods (Hallaeur and Miranda, 1981) after which estimates of genetic variances were computed as follows (Comstock et al., 1958): Within full-sib families $\left(\sigma_{\mathrm{w}}^{2}\right)=\sigma^{2}$ error $-\sigma_{\mathrm{v}}^{2}$; additive $\left(\sigma_{\mathrm{a}}^{2}\right)$ $=4$ (pooled $\sigma_{\mathrm{f}}^{2}$ and $\left.\sigma_{\mathrm{m}}^{2}\right)$; dominance $\left(\sigma_{\mathrm{d}}^{2}\right)=4\left(\sigma_{\mathrm{mf}}^{2}\right)$. Within full-sib families not additive or dominance $\left(\sigma_{\mathrm{i}}^{2}\right)=\sigma_{\mathrm{w}}^{2}-2$ (pooled $\sigma_{\mathrm{f}}^{2}$ and $\sigma_{\mathrm{m}}^{2}$ ) $-3 \boldsymbol{\sigma}_{\mathrm{mf}}^{2}$; and Total $\left(\sigma_{\mathrm{y}}^{2}\right)=2$ (poolled $\sigma_{\mathrm{f}}^{2}$ and $\left.\sigma_{m}^{2}\right)+\sigma_{m f}^{2}+\sigma_{w}^{2}$ Jarrow-sense heritability $\left(h^{2}\right)$ was estimated in the standard manner (Hallaeur and Miranda, 1981) using pooled $\sigma_{\mathrm{f}}^{2}$ and $\sigma_{\mathrm{m}}^{2}$ to compute the numerator.

Genetic and environmental variance (large population) (Expt. 2). Forty parents were employed, including selections containing diverse germplasm developed in California, Maryland, Ar- 
Table 1. Origin of strawberry clones used as parents in Expt. 1 and their reported response to $C$. fragariae.

\begin{tabular}{|c|c|c|c|}
\hline Clone & Origin & State of origin & Response \\
\hline FLA82-1142 & FLA78-1268P $\times$ Pajaro & Florida & Unknown \\
\hline MSUS40 & FLA73-1965E x LA2556 & Mississippi & Resistant \\
\hline MSUS70 & FLA76-802 x LA2556 & Mississippi & Resistant or susceptible ${ }^{z}$ \\
\hline Prelude & Titan x NC2967 & North Carolina & Susceptible \\
\hline Roseanne & NC3140 $\times$ Self & North Carolina & Resistant or susceptible ${ }^{z}$ \\
\hline Tangi & L59-2012 x L59-1938 & Louisiana & Susceptible \\
\hline
\end{tabular}

${ }^{2}$ Depends upon $C$. fragariae isolate.

kansas, North Carolina, Louisiana, Mississippi, and Florida plus two cultivars (Table 2). The parents were randomly allocated to four sets of 10 . Clones within each set were randomly designated as five males and five females that were crossed in a Comstock and Robinson (1952) Design II mating scheme. One hundred percent success with each cross would have resulted in 25 full-sib families from each set. Because of either poor seed set or lack of germination, plants from 87 out of 100 possible families were available for evaluation. From 12 to 16 seedlings per family were vegetatively propagated by runners to obtain three genetically identical plants from each seedling.

One plant originating from each seedling was inoculated with C. fragariae isolates CF-63 and MS-9 and C. acutatum isolate Mil-1 so that each isolate was tested on identical genotypes. Isolates CF-63 and MS-9 were chosen because they were morphologically distinct and appeared to differ in pathogenicity; isolate Mil-1 was chosen as representative of C. acutatum (Smith and Black, 1990). Inoculum preparation and inoculation method were the same as in Expt. 1. Plants were inoculated with isolates CF-63 and Mil-1 from 27 May to 10 June and with isolate MS9 from 3 to 14 June 1988, incubated in a dew chamber at $100 \%$ $\mathrm{RH}$ and $31 \pm 1 \mathrm{C}$ for $48 \mathrm{~h}$, then returned to a greenhouse at ambient temperatures.

All plants were rated for disease severity 20 days after inoculation using the same scale as in Expt. 1. An estimate of $\boldsymbol{\sigma}_{\mathrm{v}}^{2}$ was obtained from 321 plants from 10 clones inoculated with isolates CF-63 and Mil-1 and treated similarly to the progenies. Genetic variances were estimated in the same manner as in Expt.
1. Narrow $\left(\mathrm{h}^{2}\right)$ and broad $\left(\mathrm{H}^{2}\right)$ sense heritability estimates were computed by standard methods (Hallaeur and Miranda, 1981).

\section{Results}

Expt. 1. The mean disease severity rating for isolate Goff (2.5) was significantly lower than that for CF-63 (3.7), Fla-1 (3.7), or La-1 (3.3), indicating that $C$. acutatum produced less severe disease reaction than $C$. fragariae. Despite this difference, genetic response to the two pathogen species appears similar as indicated by a lack of genotype $\times$ isolate interactions (Table 3). Isolates were pooled to estimate genetic parameters because neither the male nor female $\times$ isolate source of variation was significant.

The additive genetic variance estimate $(0.39)$ was more than four times larger than that for dominance (0.09). Within-family variance not accounted for by additive or dominance estimates (0.39) equaled $45 \%$ of the total genetic variance $(0.86)$. The narrow-sense heritability estimate of 0.89 was very high.

Expt. 2. The mean disease severity rating of $C$. acutatum isolate Mil-1 (2.8) was again significantly lower than ratings of C. fragariae isolates MS-9 (3.4) and CF-63 (3.2). Neither the male nor female $\times$ isolate source of variation was significant (Table 4), which agrees with the results of Expt. 1. Isolates were pooled to estimate genetic parameters.

Estimates of genetic variances were computed for both male and female components because the data were unbalanced due to missing families and unequal numbers of progeny per family. Nevertheless, male and female estimates were similar in each

Table 2. Origin of strawberry clones used as parents in Expt. 2.

\begin{tabular}{|c|c|c|c|}
\hline Clone & Parentage & Clone & Parentage \\
\hline MSUS56 & LA883 x NC3843 & MSUS191 & Redchief $\times$ LA883 \\
\hline MSUS63 & Tangi $\times$ FLA73-1634 & MSUS192 & Tangi $\times$ FLA77-169 \\
\hline MSUS70 & FLA76-802 x LA2556 & MSUS194 & FLA76-577 x MDUS3771 \\
\hline MSUS74 & FLA76-570 x LA6995 & MSUS203 & FLA77-163 x Allstar \\
\hline MSUS80 & FLA76-570 x LA6995 & MSUS204 & LA883 x US78-1760AN \\
\hline MSUS97 & LA6632 $\times$ Roseanne & MSUS213 & LA7922 $\times$ FLA76-802 \\
\hline MSUS109 & LA2246 $\times$ MSUS42 & MSUS214 & MSUS31 $\times$ Dover \\
\hline MSUS112 & LA7922-A x US78-1760AN & MSUS217 & MSUS42 $\times$ Allstar \\
\hline MSUS115 & FLA76-577 × NC3920 & LA 8208 & Florida Belle x L883 \\
\hline MSUS122 & US78-1839AN x LA7517A & LA8220 & NC4093 $\times$ Dover \\
\hline MSUS125 & LA883 $\times$ NC4022 & LA8310 & LA2556 $\times$ LA6379 \\
\hline MSUS132 & LA2246 x Douglas & LA8318 & FLA76-570 x MSUS39 \\
\hline MSUS146 & MSUS42 x FLĂ73-1872 & LA8406 & MSUS42 $\times$ FLA73-1872 \\
\hline MSUS151 & MSUS42 x FLA73-1872 & LA8408 & MSUS31 x FLA73-1872 \\
\hline MSUS153 & LA7525A x US78-1760AN & LA8409 & LA7525 x US78-1769 \\
\hline MSUS159 & LA7525A x US78-1760AN & LA8410 & Unknown \\
\hline MSUS168 & FLA76-570 x NC3860 & LA8415 & US78-1839 x LA7517 \\
\hline MSUS171 & FLA76-570 x NC3860 & LA8419 & US78-1839 x LA7517 \\
\hline MSUS181 & Cardinal $\times$ FLA77-163 & Prelude & Titan x NC2967 \\
\hline MSUS190 & Florida Belle $\times$ MSUS27 & Tangi & L59-2012 x L59-1938 \\
\hline
\end{tabular}


Table 3. Mean squares from general linear model analysis of disease severity ratings in nine strawberry families inoculated with four isolates of Colletotrichum spp. (Expt. 1).

\begin{tabular}{lrc}
\hline \hline Source & df & Mean square \\
\hline Total & 1251 & \\
Isolates (I) & 3 & $28.58^{* *}$ \\
Females (F) & 2 & $78.16^{* *}$ \\
Males (M) & 2 & $16.37^{*}$ \\
$\mathrm{~F} \times \mathrm{M}$ & 4 & 6.89 \\
$\mathrm{~F} \times \mathrm{I}$ & 6 & 5.39 \\
$\mathrm{M} \times \mathrm{I}$ & 6 & 3.14 \\
$\mathrm{~F} \times \mathrm{M} \times \mathrm{I}$ & 12 & $3.91^{*}$ \\
Error & 1216 & 2.00 \\
\hline
\end{tabular}

*** Significant at $P=0.05$ and 0.01 , respectively.

Table 4. Mean squares from general linear model analysis of disease severity ratings in 87 strawberry families inoculated with three isolates of Colletotrichum spp. (Expt. 2).

\begin{tabular}{lrc}
\hline \hline Source & df & Mean square \\
\hline Total & 3695 & \\
Isolates $(\mathrm{I})$ & 2 & $84.81^{* *}$ \\
Sets $(\mathrm{S})$ & 3 & $35.20^{*}$ \\
$\mathrm{I} \times \mathrm{S}$ & 6 & $6.52^{*}$ \\
Females $(\mathrm{F}) / \mathrm{S}$ & 16 & $20.37^{* *}$ \\
$\mathrm{Males}(\mathrm{M}) / \mathrm{S}$ & 16 & $17.92^{* *}$ \\
$(\mathrm{~F} \times \mathrm{M}) / \mathrm{S}$ & 51 & $14.70^{* *}$ \\
$(\mathrm{~F} \times \mathrm{I}) / \mathrm{S}$ & 32 & -3.98 \\
$(\mathrm{M} \times \mathrm{I}) / \mathrm{S}$ & 32 & 3.07 \\
$(\mathrm{~F} \times \mathrm{M} \times \mathrm{I}) / \mathrm{S}$ & 101 & $5.84^{* *}$ \\
Error & 3436 & 3.07 \\
\hline
\end{tabular}

*,** Significant at $P=0.05$ and 0.01 , respectively.

instance $\left(\sigma_{\mathrm{a}}^{2}=0.10\right.$ and $0.17, \sigma_{\mathrm{i}}^{2}=0.67$ and 0.63 , and $\sigma_{\mathrm{y}}^{2}=$ 1.77 and 1.80 , respectively). Within-family variance not accounted for by $\sigma_{a}^{2}$ and $\sigma_{d}^{2}$ equaled $35 \%$ and $38 \%$ of the total genetic variance in females and males, respectively. In contrast to Expt. 1, the estimate of dominance $\left(\sigma_{d}^{2}=1.00\right)$ was considerably higher than that for $\sigma_{\mathrm{a}}^{2}$. A moderate level of $h^{2}(0.26$ for male and 0.37 for female) was estimated for resistance to three isolates of $C$. fragariae. Broad-sense heritability estimates $(0.85$ for male and 0.87 for female), however, were very high.

\section{Discussion}

A difference between the mean disease severity rating of $C$. acutatum and $C$. fragariae in both experiments confirmed previous results (Smith and Black, 1990) that C. acutatum produces less severe plant disease reaction than does $C$. fragariae. Colletotrichum acutatum is occasionally isolated from the crown of dying plants in the field, but it remains primarily a fruit rot organism with the capability to cause crown rot.

The lack of significant genotype $\times$ isolate variance in both experiments suggested a similar genetic response to $C$. fragariae and $C$. acutatum, which agrees with the results of Smith and Black (1990) who found that most cultivars responded similarly to the two pathogen species. A similar response to each $C$. fragariae isolate used was also indicated, but this may not be true for all isolates because Smith and Black (1990) found significant isolate $\times$ cultivar interactions when other isolates were used. The Colletotrichum spp. and race in question should probably be identified before initiating a breeding program, even though no genotype $\times$ isolate interaction was indicated in this study.

The frequency distribution of disease severity ratings was bimodal in both experiments (Fig. 1), suggesting major gene action. The large amount of within-family variance not accounted for by $\boldsymbol{\sigma}_{\mathbf{a}}^{2}$ and $\boldsymbol{\sigma}_{\mathrm{d}}^{2}$ probably indicates epistatic effects. Underestimation of $\sigma_{v}^{2}$ could inflate $\boldsymbol{\sigma}_{\mathbf{i}}^{2}$ but its similar estimates of 1.33 and 1.61 using different genotypes and isolates in different years do not suggest such a bias. Wright (1956) hypothesized that large epistatic effects would be expected when biparental crosses are made in species that are normally propagated asexually. Epistatic variance was important for various commercial traits in studies of Comstock et al. (1958), Hansche et al. (1968), Watkins and Spangelo (1968), Watkins et al. (1970), and Spangelo et al. (1971), suggesting that it is a general phenomenon in strawberry. Epistatic effects are important, but those postulated in this study occurred within families and should not affect other variances computed from among-family comparisons (Shaw et al., 1989).

The validity of other assumptions under which additive and dominance variances are estimated appears reasonable to accept although some are uncertain: 1) Regular diploid behavior of octoploid strawberry at meiosis was found by Powers (1944) and Arulsekar et al. (1981). 2) The presence of minimal cytoplasmic or other maternal effects was supported by the fact that $\sigma_{\mathrm{i}}^{2}$ was relatively large but it would have been underestimated if such effects were considerable (Comstock et al., 1958). 3) Assumption of no correlation of genotypes at different loci may not be tenable in Expt. 1 but probably is in Expt. 2 because the parents constitute broadly based germplasm. The parents were related in some instances; nevertheless, they represent a random sample of the population of interest.

The high proportion of dominance variance in Expt. 2 compared with Expt. 1 may be accounted for by the broad-based, more representative strawberry population sample in the former. These results illustrate the possible erroneous conclusions caused by using too few parents. Assuming epistasis is important in resistance to Colletotrichum spp., it could inflate $\sigma_{\mathrm{d}}^{2}$ estimates (Hallaeur and Miranda, 1981). Nevertheless, gains from selection of clonal value should be possible because of the high estimate of broad-sense heritability. The high proportion of total genetic variance estimated to consist of epistatic variance sug-

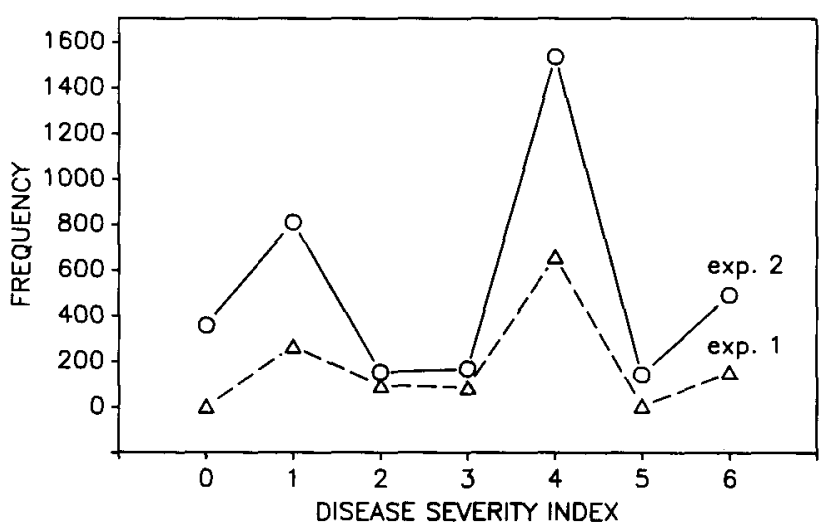

Fig. 1. Frequency distribution of disease severity ratings $(0=$ no disease symptom, $1=$ fleck on petiole, $2=$ lesions 3 to $10 \mathrm{~mm}$ long, 3 = lesions 11 to $20 \mathrm{~mm}$ long, $4=$ lesions $>20 \mathrm{~mm}$ long, $5=$ youngest leaf wilted, and $6=$ plant dead) in two populations resulting from Comstock and Robinson (1952) Design II matings of strawberry clones. Frequency equals the total number of plants inoculated with Colletotrichum fragariae isolates CF-63, LA-1, and Fla- 1 and C. acutatum isolate Goff in Expt. 1 and $C$. fragariae isolates CF-63 and MS-9 and C. acutatum isolate Mil-1 in Expt. 2 that occurred in each disease severity class. 
gests that a multistage selection/breeding procedure would be efficient. Within-family selection would permit introgression of new germplasm to introduce desirable characteristics and reduce inbreeding. Establishing a broad genetic-based population resistant to Colletotrichum spp. from which selections could be evaluated per se (using broad-sense heritability) and/or recombined to produce improved populations also appears feasible. Narrow-sense heritabilitv estimates based on this study are probably sufficient to produce moderate gains from recurrent selection. This conclusion is supported by the fact that we have observed increased levels of resistance with successive cycles of selection following phenotypic assortative mating (B.J.S., unpublished data).

\section{Literature Cited}

Arulsekar, S., R.S. Bringhurst, and V. Voth. 1981. Inheritance of PGI and LAP isozymes in octoploid cultivated strawberries. J. Amer. Soc. Hort. Sci. 106:679-683.

Comstock, R.E. and H.F. Robinson. 1952. Estimation of average dominance of genes. Hetorosis. Iowa State College Press, Ames.

Comstock, R.E., T. Kelleher, and E.B. Morrow. 1958. Genetic variation in an asexual species, the garden strawberry. Genetics 43:634646.

Hallaeur, R.R. and J.B. Miranda. 1981. Quantitative genetics in maize breeding. Iowa State Univ. Press, Ames.
Hansche, P.E., R.S. Bringhurst, and V. Voth. 1968. Estimates of genetic and environmental parameters in the strawberry. Proc. Amer. Soc. Hort. Sci. 90:338-345.

Powers, L. 1944. Meiotic studies of crosses between Fragaria ovalis and Fragaria $\times$ ananassa. J. Agr. Rev. 69:435-448.

Shaw, D.V., R.S. Bringhurst, and V. Voth. 1989. Genetic parameters estimated for an advanced cycle strawberry breeding population at two locations. J. Amer. Soc. Hort. Sci. 114:823-827.

Smith, B.J. and L.L. Black. 1986. First report of Colletotrichum acutatum on strawberry in the United States. Plant Dis. 70:1074.

Smith, B.J. and L.L. Black. 1987. Resistance of strawberry plants to Colletotrichum fiagariae affected by environmental conditions. Plant Dis. 71:834-837.

Smith, B.J. and L.L. Black. 1990. Morphological, cultural, and pathogenic variation among Colletotrichum species isolated from strawberry. Plant Dis. 74:69-76.

Spangelo, L.P.S., C.S. Hsu, S.O. Fejer, P.R. Bedard, and G. Rousselle. 1971. Heritability and genetic variance components for 20 fruit and plant characters in the cultivated strawberry. Can. J. Genet. Cytol. 13:443-456.

Watkins, R. and L.P.S. Spangelo. 1968. Components of genetic variance in the cultivated strawberry. Genetics 59:93-103.

Watkins, R., L.P.S. Spangelo, and A.T. Bolton. 1970. Genetic variance components in cultivated strawberry. Can. J. Genet. Cytol. 12:52-59.

Wright, S. 1956. Modes of selection. Amer. Naturalist 90:5-24. 